\title{
In the Classroom
}

\section{Progress in Practice: Exploring the Cooperative and Collaborative Dimensions of Group Learning}

BRIAN P. COPPOLA

Department of Chemistry

The University of Michigan

Ann Arbor, MI 48109-1055, USA

bcoppola@umich.edu

If we want our

students to

achieve in a

particular way

and not in

another, then the

structure of the

task plays a

significant role.

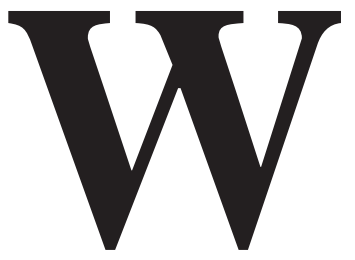

e all participate in a variety of groups as part of our daily lives, from families to social and work communities. As chemists, we are part of our college departments, our professional societies, our research groups, and so on. In graduate and undergraduate school, some of us formed peer study groups in response to the demands of those other groups that we were a part of: our

* Individuals involved in curriculum design often introduce new, modified or applied ideas about instruction that range from classroom methods to philosophies of education. In this series, Progress in Practice, we will examine progress in chemical education that is related to practices, where many recommendations have originated from areas in higher education that exist alongside of and overlap with chemistry. Rather than an exhaustive review, we will select examples, background and vocabulary that may either invite interested newcomers to explore a different area in their teaching, or provide language and precedent for individuals who wish to contextualize ideas they have developed independently.

-Brian P. Coppola, Series Editor 
formal courses. We know we are not unique in this. The popular culture, at least, is filled with portrayals of medical, law, and business students who must divide responsibility for learning a daunting amount of course material and who then teach one another as a part of their learning. Graduate research groups in chemistry are generally highly structured by their research directors where community issues are involved (group meetings and assignments, shared equipment, and representatives who obtain specialized skills such as crystallography or mass spectrometry), and move towards a less authoritative structure when developing individual initiative is the goal. Individuals depend on (and learn with) one another in all kinds of educational situations. In order to emphasize this idea, Bruffee [1] advocates the use of a phrase attributed to John Dewey: "living an associated life." As Bruffee describes it, formal education in America has been based on a philosophy of associated learning since at least the time of Benjamin Franklin. We all live and learn in an associated way. Differences in interactions vary according to the nature of a group's structure (and sometimes, although not as often, to an individual's degree of dissociation from the group).

The current renaissance in promoting structured group learning as a part of formal postsecondary coursework in science is approximately 15 years old. It is an outgrowth of recommendations for engaging students in more "active" (as opposed to "passive") learning environments [2], [3], [4], [5] as well as of a great deal of pioneering work done in undergraduate engineering education [6], [7], [8], [9] and in the precollege "Cooperative Learning" movement [10], [11]. Structured peer group work has been a constant feature in disciplines that involve a great deal of writing, where there is an expectation for students to learn from one another. Not surprisingly, chemists have a long tradition of designing group laboratory experiments for undergraduates [12], [13], [14], [15], [16], [17], [18], even if they are used infrequently and do not dominate laboratory textbooks in the same way that lists of individual exercises do. Before 1980, published examples of group work in chemistry lecture courses are rare, although noted educator Frank C. Whitmore described an example as early as 1925 [19]. The current cycle of designing and using group work is defined by the introduction of the terms collaborative learning and cooperative learning [1], [20], which have been embraced by individuals in and beyond the chemical education community [21], [22], [23], [24], [25], [26], [27], [28], [29], [30], [31], [32], [33], [34], [35], [36].

Neither "collaborative learning" nor "cooperative learning" are intended to be interchangeable euphemisms for "having students work in groups." Individuals are still wrest- 
ling, however, with the distinctions between and usage guidelines for these terms. Bruffee [1] and Matthews, et al. [21] have both addressed this question. Bruffee maintains that they are "two versions of the same thing," where the advocates in "both groups know they are reinventing the wheel." Matthews, et al., acknowledge the historical fact that two different traditions developed independently, but in clearly defining the differences and similarities they also "wish to lay the groundwork for a convergence of purpose." It is common to find one of the skills (use of collaboration, for example) listed as an attribute of the other (as Felder does [8] in describing the elements of Cooperative Learning outlined by Johnson, et al. [37]). This sort of conundrum, as we have proposed [38], is a typical consequence of following a false assumption that cooperative and collaborative learning represent a dualistic system (comprised of opposites, where characteristics of one attribute can be used to define the other) rather than a synergistic one. To resolve this, we view the issue of how group work is structured, described in the earlier examples, as the context in which separate cooperative and collaborative dimensions arise. A literal reading of differences in the words cooperative and collaborative is useful. Collaborative issues are related to the organization of the "labor." Collaboration relates to the structure of the knowledge that is needed to accomplish a given task, and the benefit that comes from individuals organizing themselves so that responsibilities within a task are matched to specific skills. The organizational opposite of this collaborative sense is a "commutative" one (or perhaps "equalitarian" is a better word choice) where each participant is (can be) held equally responsible for every part of a task or outcome. Cooperative issues arise that are related to how individuals "operate" in group situations. Cooperation versus competition is a familiar dualism that is used to characterize the spectrum for how individuals operate within a group.

In order for our proposition for relating the cooperative and collaborative dimensions to be useful, it should both help to resolve the problems that exist in the literature and improve one's understanding of the ideas. The following lists summarize the published attributes for group structure, traditional cooperative and collaborative learning, and the general areas of agreement between them, all of which are in the references accompanying this article.

I. Structural features that arise in organized group work depend on:

- the design and assignment of tasks

- the nature, involvement and power of a group leader 
- the extent to which formal training in group work occurs, including how groups are formulated

- underlying beliefs about how knowledge is acquired

- differences in educational outcomes (from basic informational knowledge to critical analysis skills)

- personal and social development levels of the participants

- assignment of individual and group accountability

II. The cooperative learning tradition:

- promotes social integration and actively organizes dynamics within the group

- makes the group accountable for collective learning

- places the center of authority with the instructor

- is most effective for basic knowledge where clear definitions or agreement exist

- depends on hierarchical authority and discourages dissent and competition

III. The collaborative learning tradition:

- promotes a great deal of self-governance and accountability by individuals

- turns debate back to the group for decision-making

- uses recorders and facilitators rather than authoritative leaders

- evaluates on the basis of individual contributions

- promotes competition between groups, and foments questioning assumptions as well as authority

- is most effective where "conditional knowledge" is involved rather than issues of general acceptance and agreement; that is, for knowledge that depends on a more explicit set of conditions, such as at the edges of a debate, where the lack of consensus about underlying assumptions or their relative weights (the conditions) leads to an array of interpretations

IV. There is general agreement, for all group-based work, that it:

- promotes more active engagement by students in their own learning

- emphasizes the role of teachers and students as learners who benefit from teaching one another

- creates the opportunity to develop important higher order interpersonal and group skills

- can promote the development of self-learning skills so that students can deal with new information rather than only relying on authorities to 'cover' content 


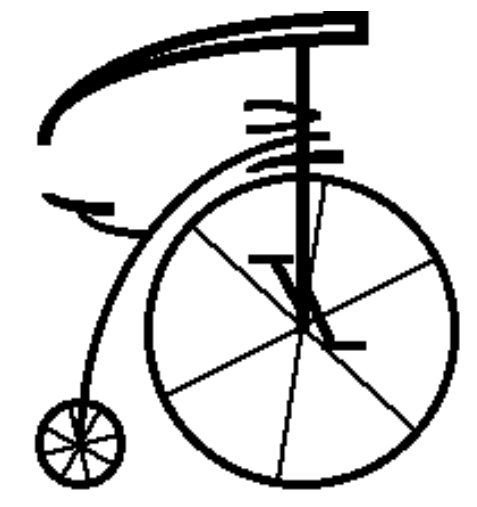

FIGURE 1. A PENNY-FARTHING BICYCLE.

Specific examples of both cooperative and collaborative learning tasks can be found in the chemical education literature or adapted from other disciplines. As chemists and chemistry instructors in our own classes, we are ultimately responsible for deciding which of our instructional goals are best suited to what sort of teaching method (hence the importance of a rational and well-articulated set of goals). To capture our synergistic view of the cooperative and collaborative learning dimensions of group work, we will use the metaphorical group task of constructing a "penny-farthing" bicycle (Figure 1). In Figure 2, we have represented how understanding the different roles that group structure plays defines the two attributes of cooperative and collaborative learning. The cooperative tradition embodies an externally imposed structure. The collaborative tradition is based on the valuing of an internally developed structure and the contributions from individuals. For the sake of our example, we have assumed that the current understanding of building penny-farthing bicycles includes a larger wheel with 6 spokes and a smaller wheel with 8 spokes.

As posited in Figure 2, the outcome from traditionally defined cooperative learning would be a well-constructed penny-farthing bicycle (upper left-hand quadrant). Students in the learning groups would have been instructed in the expectations of what a penny-farthing bicycle is, and an instructor would supervise the group's mastery of the skills required to reproduce the dogmatic version of the task's objective. Credit would be assigned to all members of the group equally for their accomplishments. Under traditional collaborative learning conditions (lower right-hand quadrant), early planning sessions would raise the difference in the number of spokes as an issue. When it is discovered that a sturdier large wheel results from adding spokes, a new task force made up of small- and large-wheel- 


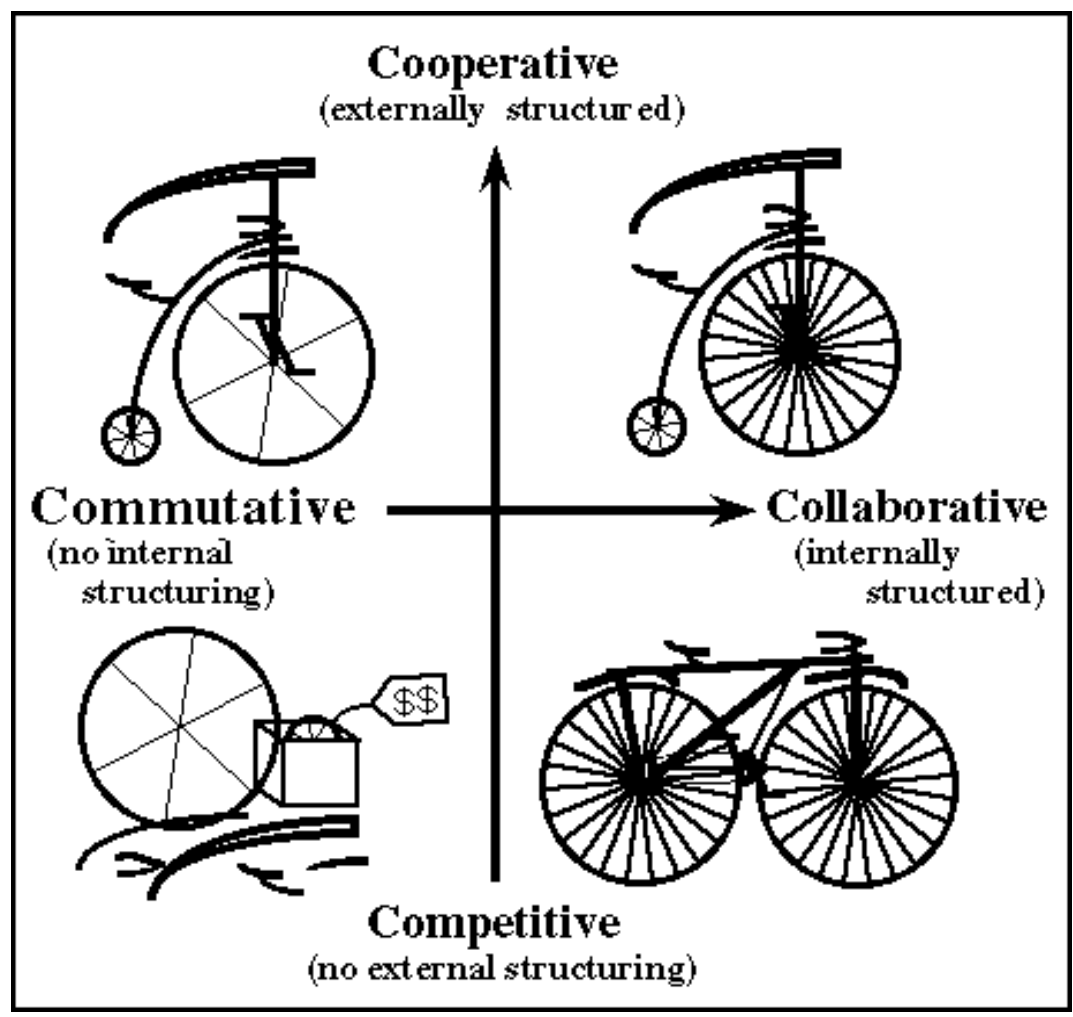

FIGURE 2. A SYNERGISTIC VIEW OF COOPERATIVE AND COLLABORATIVE LEARNING.

makers might examine the circumference-to-spoke ratio problem. Given the importance of this discovery, and in anticipation of financial reward and professional recognition that could result, the original teams might not easily resolve the issue of who gets to develop the invention from the prototypes. In an extreme scenario, both teams end up deciding to invest their efforts in the new 24-spoke idea, each willing to risk the chance of coming in second because of the promise of coming in first. At the next meeting, when neither team has given up its claim to the large wheel, the wheel-makers propose a multidisciplinary session with the framers, the seat-makers and the bell crew and end up advancing the concept of bicycles substantially (although it takes much longer and does not meet the original need to manufacture a penny-farthing design). In the synergistic domain (upper right-hand quadrant), because there is an acknowledged project leader (principal investigator?), the original task is accomplished; furthermore, the 24-spoke improvement is incorporated into the larger wheel after the first or second planning session. Although work in the isolated domain (lower left-hand quadrant) can produce well-formulated parts, the benefits resulting from necessary group interactions are difficult to obtain. Just as for students who encounter the need to know how to express themselves for the first time 
while they are actually taking an exam, the assembly occurs at exactly the worst time, under the highest stress, and as a group exercise it is a failure, although it is possible that a solitary individual might ultimately produce a bicycle at some point.

The differences in outcomes represented by three of the four quadrants in Figure 2 provide compelling analogies for the kinds of effects we are all interested in promoting during the course of a student's education. Do we want students to be well-informed about the existing dogma? Do we want them to be able to make improvements within the context of existing knowledge? Do we want them to achieve in ways that go beyond our traditions in ways that are founded on the strengths of what has come previously? The answer to all of these questions, naturally, is yes. As instructors, we need to assess the desirability of a given kind of outcome with respect to our instructional goals when designing educational tasks. If we want our students to achieve in a particular way and not in another, then the structure of the task plays a significant role. Indeed, the most sophisticated skills to develop for doing group work are [1] how to match a problem with the kind of organization that is most effective, and [2] how to turn an existing yet ineffective organization into a more productive one. In education, advocates for group work have provided a blueprint for enabling students to develop all of these skills by carefully considering the effects of group structure, task design and the synergistic dimensions of collaborative and cooperative learning.

\section{REFERENCES}

1. Bruffee, K. A. "Sharing Our Toys" Change 1995, 27 (1), 12.

2. Steiner, R. "Encouraging Active Student Participation in the Learning Process" J. Chem. Educ. 1980, 57, 433.

3. Noel, P. "Maximizing Student Involvement in Learning” J. Chem. Educ. 1990, 67, 1004.

4. Worrell, J. H. "Creating Excitement in the Chemistry Classroom: Active Learning Strategies" J. Chem. Educ. 1992, 69, 913.

5. Holme, T. A. "Using the Socratic Method in Large Lecture Courses: Increasing Student Interest and Involvement by Forming Instantaneous Group” J. Chem. Educ. 1992, 69, 974.

6. Goldstein, H. "Learning through Cooperative Groups" Engineering Education, 1982, November, 171.

7. Wandersee, J. "Mantras, False Dichotomies, and Science Education Research" Journal of Research in Science Teaching 1991, 28, 211-212. 
8. Felder, R. M.; Brent, R. "Cooperative Learning in Technical Courses: Procedures, Pitfalls, and Payoffs” ERIC Document Reproduction Service, October 1994.

9. Weimer, M. "Making Group Projects Work” The Teaching Professor 1988, 2 (3), 8.

10. Tobin, K.; Tippins, D. J.; Gallard, A. J. "Research on Instructional Strategies for Teaching Science." In, Gabel, D. L. Handbookfor Research on Science Teaching and Learning MacMillan: New York, 1994, pp. 79-81, 113-114.

11. The International Association for the Study of Cooperation in Education (IASCE) was organized in 1979. Its newsletter is now available as a journal called "Cooperative Learning."

12. Leisten, J. A. "A Group Experiment on the Hammett Sigma-Rho Relation” J. Chem. Educ. 1961, 38,302 .

13. Wentworth, W. E.; Drake, G. M.; Hirsch, W.; Chen, E. "Molecular Charge Transfer Complexes: A Group Experiment in Physical Chemistry" J. Chem. Educ. 1964, 41, 373.

14. Zuehlke, R. W. "Laboratory Group Exercises in Acid-Base Theory" J. Chem. Educ. 1962, 39, 354.

15. Buono, J. A.; Fasching, J. L. "Initiative, Ingenuity, Creativity, and Chemistry, Too? A Group Approach to Analytical Projects" J. Chem. Educ. 1973, 50, 616.

16. Jaques, D. "Hydrolysis of Ethyl Acetate in Concentrated Sulfuric Acid. A Group Experiment for Advanced Students" J. Chem. Educ. 1971, 48, 623.

17. Barnard, P. W. C. "The Menschutkin Reaction: A Group Experiment in a Kinetic Study" J. Chem. Educ. 1981, 58, 282.

18. Walters, J. P. “Role-Playing Analytical Chemistry Laboratories” Anal. Chem. 1991, 63, 977A.

19. Hurley, C. N. "Study Groups in General Chemistry" Journal of Chemical Education 1993, 70, $651-652$.

20. Walters, J. P. "Role-Playing Analytical Chemistry Laboratories" Analytical Chemistry 1991, 63, 977-985A.

21. Josephsen, J. "From Freshman Student to Upper-Secondary School Teacher in Chemistry: A New Approach with Projects and Group Work" J. Chem. Educ. 1985, 62, 426.

22. Fasching, J. L.; Erikson, B. L. "Group Discussions in the Chemistry Classroom and the ProblemSolving Skills of Students” J. Chem. Educ. 1985, 62, 842.

23. Smith, M. E.; Hinckley, C. C.; Volk, G. L. "Cooperative Learning in the Undergraduate Laboratory" J. Chem. Educ. 1991, 68, 413. 
24. Hurley, H. C. "Study Groups in General Chemistry" J. Chem. Educ. 1993, 70, 651.

25. Ross, M. R.; Fulton, R. B. "Active Learning Strategies in the Analytical Chemistry Classroom” J. Chem. Educ. 1994, 71, 141.

26. Tucker, S. A.; Acree, Jr., W. E. "A Student-Designed Analytical Laboratory Method” J. Chem. Educ. 1985, 62, 842 .

27. Cooper, M. M. “Cooperative Chemistry Laboratories” J. Chem. Educ. 1994, 71, 307.

28. Cooper, M. M. “Cooperative Learning” J. Chem. Educ. 1995, 72, 162.

29. Cooper, M. M.; Kerns, T. "Should We Use Cooperative Learning in College Chemistry?" (http://tigerched.clemson.edu/cooplearn/paper.html)

30. Kandel, M. "Personalized Laboratory Experiences through Cooperative Projects" J. Chem. Educ. 1994, $71,71$.

31. Garafolo, F.; LoPresti, V. "Evolution of an Integrated College Freshman Curriculum" Journal of Chemical Education 1993, 70, 352-359.

32. Roth, W.-M. "In the Name of Constructivism: Science Education Research and the Construction of Local Knowledge" Journal of Research in Science Teaching 1993, 30, 799-803.

33. Dinan, F. J.; Frydrychowski, V. A. "A Team Learning Method for Organic Chemistry" J. Chem. Educ. 1995, 72, 429.

34. Bodner, G. M. "Constructivism: A Theory of Knowledge” Journal of Chemical Education 1986, $63,873-878$.

35. Coppola, B. P.; Lawton, R. G. "'Who Has the Same Substance that I Have?' A Blueprint for Collaborative Learning Activities.” J. Chem. Educ. 1995, 72, 1120.

36. Delaware, D. L.; Fountain, K. R. "Computational Chemistry in the First Year Organic Course" J. Chem. Educ. 1996, 73, 116.

37. Schulman, L. S. "Those Who Understand: Knowledge Growth in Teaching” Educational Researcher 1986, 15(2), 4-14.

38. Coppola, B. P.; Daniels, D. S. "Structuring the Liberal (Arts) Education in Chemistry" The Chemical Educator, in press. 